Revista Eletrônica de Ciência Administrativa (RECADM) - ISSN 1677-7387

Faculdade Cenecista de Campo Largo - Coordenação do Curso de Administração

v. 3, n. 2, nov./2004 - http://revistas.facecla.com.br/index.php/recadm/

\title{
A UNIVERSIDADE DO SÉCULO XXI RUMO AO DESENVOLVIMENTO SUSTENTÁVEL
}

\section{AUTORIA: Maria Elisabeth Pereira Kraemer}

Contadora, CRC/SC no 11.170, Professora e Integrante da Equipe de Ensino e Avaliação na Pró-Reitoria de Ensino da UNIVALI - Universidade do Vale do Itajaí. Mestre em Relações Econômicas Sociais e Internacionais pela Universidade do Minho-Portugal. Doutoranda em Ciências Empresariais pela Universidade do Museu Social da Argentina. Integrante da Corrente Científica Brasileira do Neopatrimonialismo e da ACIN - Associação Científica Internacional Neopatrimonialista.

ENDEREÇO: Avenida Joca Brandão no 111, Edifício Dona Emília, apto 902 - Centro. CEP 88.301-300 ITAJAÍ - SC -

E-mail: beth.kraemer@terra.com.br

TELEFONE/FAX: (0XX) 47-3446558 


\title{
Revista Eletrônica de Ciência Administrativa (RECADM) - ISSN 1677-7387 Faculdade Cenecista de Campo Largo - Coordenação do Curso de Administração v. 3, n. 2, nov./2004 - http://revistas.facecla.com.br/index.php/recadm/
}

\section{A UNIVERSIDADE DO SÉCULO XXI RUMO AO DESENVOLVIMENTO SUSTENTÁVEL}

\begin{abstract}
Resumo
As atividades humanas sobre o meio ambiente vêm se intensificando ao longo do tempo e de forma mais acentuada a partir da Revolução Industrial, no final do século XIX, resultando na miséria, na exclusão social e econômica, no consumismo, no desperdício e na degradação ambiental. A universidade é o lugar privilegiado para uma educação dirigida às exigências de nossos tempos. Atribuí-se a ela a responsabilidade de educar para o desenvolvimento sustentável, quer diretamente os seus alunos, quer por influência, junto de decisores e outros agentes-chave implicados no processo.
\end{abstract}

Palavras-chave: desenvolvimento sustentável, educação, meio ambiente e universidade.

\begin{abstract}
Abstrat
The human activities on the environment are intensifying along the time and in a more accentuated way starting from the Industrial Revolution, in the end of the XIX century, resulting in poverty, social and economic exclusion, consumerism, waste and environmental degradation. The university is the privileged place for an education driven to the demands of our time. It is attributed to it the responsability of educating for the maintainable development, as its students directly or for influence of its managers and other key agents implied in the process.
\end{abstract}

Keywords: education, environment, maintainable development, university.

\section{1 - Introdução}

O rápido crescimento demográfico, o esbanjamento dos recursos naturais e a degradação do meio ambiente, a pobreza persistente de grande parte da humanidade, a opressão, a injustiça e a violência de que padecem ainda milhões de pessoas exigem ações corretivas de grande envergadura.

Segundo Mayor (1998), a educação é a chave do desenvolvimento sustentável, auto-suficiente - uma educação fornecida a todos os membros da sociedade, segundo modalidades novas e com a ajuda de tecnologias novas, de tal maneira que cada um se beneficie de chances reais de se instruir ao longo da vida. Devemos estar preparados, em todos os países, para remodelar o ensino, de forma a promover atitudes e comportamentos que sejam portadores de uma cultura da sustentabilidade.

É aí que entram em jogo as universidades, assim como todos os estabelecimentos de ensino superior, que assumem uma responsabilidade essencial na preparação das novas gerações para um futuro viável. Pela reflexão e por seus trabalhos de pesquisa básica, esses estabelecimentos devem não 


\section{Revista Eletrônica de Ciência Administrativa (RECADM) - ISSN 1677-7387 Faculdade Cenecista de Campo Largo - Coordenação do Curso de Administração v. 3, n. 2, nov./2004 - http://revistas.facecla.com.br/index.php/recadm/}

somente advertir, ou mesmo dar o alarme, mas também conceber soluções racionais. Devem tomar a iniciativa e indicar possíveis alternativas, elaborando esquemas coerentes para o futuro. Devem, enfim, fazer com que se tome consciência maior dos problemas e das soluções através de seus programas educativos e dar, eles mesmos, o exemplo.

Esta tarefa se materializa na promoção de programas de ensino novos e/ou reorientados, de acesso mais abrangente e contínuo, na criação de painéis de peritos que aconselham os governos e fazem um acompanhamento crítico da atuação destes e de outros agentes da sociedade.

Neste sentido, os trabalhos desenvolvidos dentro das instituições de ensino de nível superior têm um efeito multiplicador, pois cada estudante, convencido das boas idéias da sustentabilidade, influencia o conjunto, a sociedade, nas mais variadas áreas de atuação.

A educação está sendo, nos dias de hoje, repensada como uma preparação para a vida: trata-se de garantir a segurança do emprego e a aptidão para o trabalho, de permitir a cada um satisfazer às demandas de uma sociedade em rápida evolução, assim como as mudanças tecnológicas que condicionam hoje, direta ou indiretamente, cada aspecto da existência e, finalmente, de conseguir responder à busca da felicidade, do bem-estar e da qualidade de vida.

\section{2 - Meio ambiente}

A concepção ecológica concebe o universo como um todo interligado e interconectado entre si. Reconhece a interdependência fundamental de todos os seres vivos, não como uma coleção de partes dissociadas, mas como uma rede de fenômenos articulados e fortemente imbricados, dentro da qual seres humanos e sociedades participam de forma cíclica dos processos da natureza.

Neste sentido, Bertalanffy (1977), com sua Teoria Geral dos Sistemas, enfatiza que tudo está unido a tudo e que cada organismo não é um sistema estático fechado ao mundo exterior, mas sim um processo de intercâmbio com o meio circunvizinho, ou seja, um sistema aberto num estado quase estacionário, onde materiais ingressam continuamente, vindos do meio ambiente exterior, e neste são deixados materiais provenientes do organismo.

Para Bateson (1987), um sistema vivo não se sustenta somente com a energia que recebe de fora, mas fundamentalmente pela organização da informação que o sistema processar.

Esse processo de interligação foi sabiamente descrito no século passado por um chefe índio, numa carta enviada ao Presidente dos Estados Unidos que, de acordo com Dias (1993, p. 47), em sua obra A carta do Chefe Indígena Seattle, dizia: "[...] ensinem às suas crianças o que ensinamos às nossas, que à Terra é nossa mãe. Tudo o que acontecer a Terra, acontecerá aos filhos da Terra. Se os homens cospem no solo, estão cuspindo em si mesmos[...] à Terra não pertence ao homem; o homem pertence a Terra[...] todas as coisas estão ligadas como o sangue que une uma família. Há uma ligação em tudo. Os rios são nossos irmãos, saciam nossa sede". 


\section{Revista Eletrônica de Ciência Administrativa (RECADM) - ISSN 1677-7387 Faculdade Cenecista de Campo Largo - Coordenação do Curso de Administração v. 3, n. 2, nov./2004 - http://revistas.facecla.com.br/index.php/recadm/}

Foi com a Revolução Industrial que o homem começou realmente a transformar a face do planeta, a natureza de sua atmosfera e a qualidade de sua água. O meio ambiente está sendo agredido, devido ao rápido crescimento da população humana, que provoca declínio cada vez mais acelerado de sua qualidade e de sua capacidade para sustentar a vida.

O impacto da espécie humana sobre o meio ambiente tem sido comparado, por alguns cientistas, às grandes catástrofes do passado geológico da Terra. A humanidade deve reconhecer que agredir o meio ambiente põe em perigo a sobrevivência de sua própria espécie e pensar que o que está em jogo não é uma causa nacional ou regional, mas sim a existência da humanidade como um todo. É a vida que está em jogo. Não podemos conceber um ecossistema sem o homem, não podemos encontrar o homem sem algum ecossistema.

Com todos os desastres que têm acontecido com o meio ambiente, percebemos que o ser humano tem sido capaz de modificar seu meio ambiente para adaptá-lo às suas necessidades.

Com o rápido crescimento da população, criou-se uma demanda sem precedentes, que o desenvolvimento tecnológico pretende satisfazer, submetendo o meio ambiente a uma agressão que está provocando o declínio cada vez mais acelerado de sua qualidade e de sua capacidade para sustentar a vida.

Um dos impactos que o uso de combustíveis fósseis tem produzido sobre o meio ambiente terrestre é o aumento da concentração de dióxido de carbono (CO2) na atmosfera, dando lugar a um aumento da temperatura global da Terra.

Outros males importantes causados pelo ser humano ao meio ambiente são o uso de pesticidas que contaminam regiões agrícolas e interferem no metabolismo do cálcio das aves; a erosão do solo, que está degradando de 20 a 35\% das terras de cultivo de todo o mundo; a perda das terras virgens; o crescente problema mundial do abastecimento de água, como conseqüência do esgotamento dos aqüíferos subterrâneos, assim como pela queda na qualidade e disponibilidade da água e a destruição da camada de ozônio.

Percebe-se, portanto, que hoje os problemas vividos no mundo são realmente em decorrência da intervenção humana no planeta e nos ecossistemas. A título de exemplo, podemos citar: destruição da biodiversidade ou a extinção de espécies; destruição progressiva da camada de ozônio por gases; efeito estufa ou aquecimento global; crescimento da população mundial; poluição e indisponibilidade de água potável.

Desde a década de 50, a deterioração ambiental e sua relação com o estilo de crescimento econômico já eram objeto de estudo e preocupação internacional. Cita-se o teólogo luterano Albert Shweitzer, filósofo, organista intérprete de Bach e médico missionário que em 1952 recebeu o Prêmio Nobel da Paz por popularizar a ética ambiental e pelos seus esforços em defesa da "Irmandade das Nações". Durante conferência proferida em 20 de outubro de 1952 na Academia Francesa de Ciências 


\section{Revista Eletrônica de Ciência Administrativa (RECADM) - ISSN 1677-7387 Faculdade Cenecista de Campo Largo - Coordenação do Curso de Administração v. 3, n. 2, nov./2004 - http://revistas.facecla.com.br/index.php/recadm/}

(Paris), sobre o tema "O problema da ética na evolução do pensamento", ele declarou: "quando o homem aprender a respeitar até o menor ser da criação, seja animal ou vegetal, ninguém precisará ensiná-lo a amar seu semelhante".

Nos anos 60, nos Estados Unidos, houve uma profunda mudança na atitude do povo americano com relação à necessidade de normas ambientais federais, suscitada pela obra "Silent Spring" (Primavera Silenciosa), de Rachel Carson, uma bióloga marinha norte-americana que provocou os políticos à ação. O livro, publicado em 1962, presidiu o rito de passagem para o momento novo na história humana: o da preocupação com os rumos do desenvolvimento próprio da sociedade industrial.

"Primavera Silenciosa" relata os efeitos da má utilização dos pesticidas e inseticidas químicosintéticas, alertando sobre as conseqüências danosas de inúmeras ações humanas sobre o ambiente.

Carson iniciou o debate sobre o custo ambiental dessa contaminação para o homem. Já nessa época, apontava para os prejuízos do uso de produtos químicos no controle de pragas e doenças, advertindo que estavam interferindo nas defesas naturais do próprio ambiente e, segundo Dias (1993, p. 54), a autora dizia que "nós permitimos que esses produtos químicos fossem utilizados com pouca ou nenhuma pesquisa prévia sobre seu efeito no solo, na água, animais selvagens e sobre o próprio homem". O livro teve os direitos comprados por uma multinacional de agroquímica e, diz-se, isto impede sua republicação.

Nos últimos anos, a preocupação em defender a natureza passou a ser mundial, devido a afirmações aterradoras como:

$\sqrt{ }$ Nosso planeta está poluído, sua temperatura se eleva, as erosões progridem, as áreas agrícolas irrigáveis diminuem, a população aumenta e os ecossistemas sofrem efeitos devastadores.

$\sqrt{ }$ Mudar a economia mundial, de acordo com o novo modelo de desenvolvimento ambientalmente mais adequado, é a única alternativa para a sobrevivência a longo prazo da humanidade.

$\sqrt{ }$ Os países desenvolvidos têm hoje menos de 25\% da população mundial, mas consomem $75 \%$ de toda a energia produzida, $70 \%$ dos combustíveis comercializados, $85 \%$ dos produtos da madeira e $72 \%$ do aço.

Portanto, fica clara a importância da questão ambiental em qualquer discussão e também dentro dos debates da sociedade, no sentido de enfatizar a consciência de preservação do meio e a evolução para a gestão da sustentabilidade, porque, a cada dia, ficam evidentes as conseqüências das agressões que o homem comete contra a natureza.

\section{3 - A expressão “Desenvolvimento Sustentável” entra em cena}

O modelo de crescimento econômico gerou enormes desequilíbrios. Se, por um lado, nunca houve tanta riqueza e fartura no mundo, por outro lado, a miséria, a degradação ambiental e a poluição aumentam dia a dia. Diante dessa constatação, surge a idéia do desenvolvimento sustentável, buscando 


\section{Revista Eletrônica de Ciência Administrativa (RECADM) - ISSN 1677-7387 Faculdade Cenecista de Campo Largo - Coordenação do Curso de Administração v. 3, n. 2, nov./2004 - http://revistas.facecla.com.br/index.php/recadm/}

conciliar o desenvolvimento econômico à preservação ambiental e, ainda, ao fim da pobreza no mundo. Fortalece-se a percepção de que é imperativo desenvolver, sim, mas sempre em harmonia com as limitações ecológicas do planeta, ou seja, sem destruir o ambiente, para que as gerações futuras tenham chance de existir e viver bem, de acordo com as suas necessidades (melhoria da qualidade de vida e das condições de sobrevivência).

As metas do desenvolvimento sustentável são:

$\sqrt{ }$ A satisfação das necessidades básicas da população (educação, alimentação, saúde, lazer, etc.).

$\sqrt{ }$ A solidariedade para com as gerações futuras (preservar o ambiente de modo que elas tenham chance de viver).

$\sqrt{ }$ A participação da população envolvida (todos devem se conscientizar da necessidade de conservar o ambiente e fazer cada um a parte que lhe cabe para tal).

$\sqrt{ }$ A preservação dos recursos naturais (água, oxigênio, etc).

$\sqrt{ }$ A elaboração de um sistema social, garantindo emprego, segurança social e respeito a outras culturas (erradicação da miséria, do preconceito e do massacre de populações oprimidas, como, por exemplo, os índios).

$\sqrt{ }$ A efetivação dos programas educativos.

A educação ambiental é parte vital e indispensável na tentativa de se chegar ao desenvolvimento sustentável, pois é a maneira mais direta e funcional de se atingir pelo menos uma de suas metas: a participação da população.

Educação para a Vida Sustentável envolve uma pedagogia que coloca a compreensão da vida como seu ponto central. O educando experimenta um aprendizado no mundo real que supera nossa alienação da natureza, o que reacende um sentido de pertinência e desenvolve um currículo que ensina às nossas crianças os princípios básicos da ecologia, tais como:

$\sqrt{ }$ aquilo que uma espécie desperdiça é a comida da outra espécie e a matéria circula continuamente pela da teia da vida;

$\sqrt{ }$ a energia que guia os ciclos ecológicos emana do sol;

$\checkmark$ a diversidade assegura a resiliência;

$\sqrt{ }$ a vida, desde o seu início, há mais de três bilhões de anos, não tomou o planeta por combate, mas por atuar em rede.

Essa pedagogia sugere o planejamento de um currículo integrado, enfatizando o conhecimento contextual, no qual os vários assuntos são entendidos como recursos a serviço de um foco central. Uma maneira ideal de alcançar a integração é aproximar-se da chamada 'aprendizagem por projetos", que consiste em facilitar as experiências de aprendizagem ao envolver alunos em projetos complexos e contemporâneos, através dos quais eles desenvolvam e apliquem habilidades e conhecimentos. 


\section{Revista Eletrônica de Ciência Administrativa (RECADM) - ISSN 1677-7387 \\ Faculdade Cenecista de Campo Largo - Coordenação do Curso de Administração v. 3, n. 2, nov./2004 - http://revistas.facecla.com.br/index.php/recadm/}

Uma das formas de levar a educação ambiental à comunidade é pela ação direta do professor na sala de aula e em atividades extracurriculares. Por meio de atividades como leitura, trabalhos escolares, pesquisas e debates, os alunos poderão entender os problemas que afetam a comunidade onde vivem, a refletir e criticar as ações que desrespeitem e, muitas vezes, destroem um patrimônio que é de todos.

Os professores são a peça fundamental no processo de conscientização da sociedade dos problemas ambientais, pois buscarão desenvolver, em seus alunos, hábitos e atitudes sadios de conservação ambiental e respeito à natureza, transformando-os em cidadãos conscientes e comprometidos com o futuro do país.

Além disso, desenvolvimento sustentável introduz uma dimensão ética e política que considera o desenvolvimento como um processo de mudança social, com conseqüente democratização do acesso aos recursos naturais e distribuição eqüitativa dos custos e benefícios do desenvolvimento.

O grande desafio do século 21 é, então, o de mudar o sistema de valores que está por trás da economia global, de modo a torná-lo compatível com as exigências da dignidade humana e da sustentabilidade ecológica.

\section{4 - A nova missão do ensino superior: educar para o desenvolvimento sustentável}

Segundo Morin (2003), os saberes necessários à educação do futuro não têm nenhum programa educativo, escolar ou universitário. Para ele, não estão concentrados no ensino fundamental, no médio, nem no ensino universitário, mas abordam problemas específicos para cada um desses níveis. Eles dizem respeito aos buracos negros da educação, completamente ignorados, subestimados ou fragmentados nos programas educativos. Programas esses que, na opinião do autor, devem ser colocados no centro das preocupações sobre a formação dos jovens, futuros cidadãos.

Um dos saberes necessários à educação, para Morin (2003), é a condição planetária, sobretudo na era da globalização. Esse fenômeno que estamos vivendo hoje, em que tudo está conectado, é um outro aspecto que o ensino ainda não tocou, assim como o planeta e seus problemas, a aceleração histórica, a quantidade de informação que não conseguimos processar e organizar. Existe neste momento um destino comum a todos os seres humanos.

Compreender a noção de desenvolvimento sustentável na prática educativa é uma noção que continua a ter um sentido muito vago. O mundo desenvolvido não mostra grande entusiasmo perante tal obrigação. Ao contrário, os países em desenvolvimento reconhecem a seriedade da questão, dizendo - e o argumento tem perfeita justificação - que vivem há muitos anos consumindo apenas o estritamente necessário e que têm, pois, o direito de dispor no futuro de uma fatia maior dos recursos.

Para ter acesso a uma melhor qualidade de vida, devemos melhorar os nossos conhecimentos. Maturana (1998) diz que o verdadeiro conhecimento não leva ao controle ou à tentativa de controle, mas leva ao entendimento, à compreensão, a uma harmônica e ajustada aos outros e ao meio. Para ele, 


\section{Revista Eletrônica de Ciência Administrativa (RECADM) - ISSN 1677-7387 Faculdade Cenecista de Campo Largo - Coordenação do Curso de Administração v. 3, n. 2, nov./2004 - http://revistas.facecla.com.br/index.php/recadm/}

conhecer é viver, viver é conhecer. Diz ainda que todo conhecer é uma ação efetiva que permite a um ser vivo continuar sua existência no mundo que ele mesmo traz à tona ao conhecê-lo.

É preciso progredir no campo da ciência e da tecnologia, das ciências sociais e humanas. Para garantir a qualidade a nível humano, é preciso melhorar também o sistema de valores. A sabedoria consiste, exatamente, na íntima aliança entre conhecimentos e valores.

É aí que entram em jogo as universidades, assim como todos os estabelecimentos de ensino superior, que assumem uma responsabilidade essencial na preparação das novas gerações para um futuro viável. Pela reflexão e por seus trabalhos de pesquisa básica, esses estabelecimentos devem não somente advertir, ou mesmo dar o alarme, mas também conceber soluções racionais. Devem tomar a iniciativa e indicar possíveis alternativas, elaborando esquemas coerentes para o futuro. Devem, enfim, fazer com que se tome consciência maior dos problemas e das soluções através de seus programas educativos e dar, eles mesmos, o exemplo.

Os trabalhos desenvolvidos dentro das instituições de ensino de nível superior têm um efeito multiplicador, pois cada estudante, convencido das boas idéias da sustentabilidade, influencie o conjunto, a sociedade, nas mais variadas áreas de atuação.

Todos os estabelecimentos de ensino superior estão bastante conscientes do papel que devem cumprir na preparação das novas gerações para um futuro viável. As universidades envolvidas partilham a convicção de que o progresso econômico e a proteção ambiental estão indissoluvelmente ligados. Um não tem futuro sem o outro como demonstra a figura 1

Figura 1 - Interpretação do Desenvolvimento Sustentável

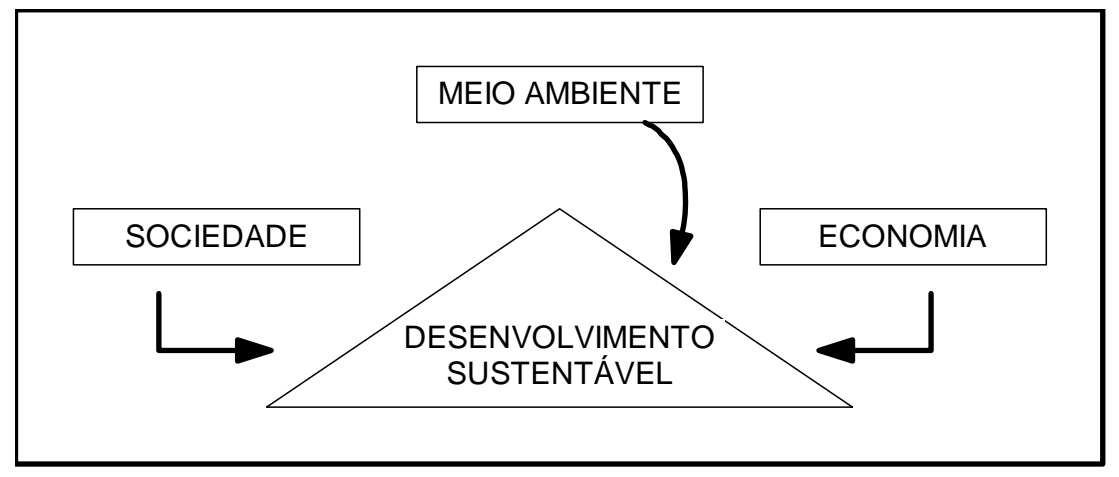

Adaptado de González \& Abadía (2002, p. 85)

Para Kornhauser (2001), a educação é o cimento da construção do desenvolvimento humano sustentável. É preciso elaborar estratégias e programas de educação relacionados com o ambiente, que abranjam tanto o ensino escolar como a educação informal, que adotem a perspectiva da educação permanente a ser desenvolvida pelos poderes públicos, o setor produtivo, o comércio e as comunidades locais. 


\section{Revista Eletrônica de Ciência Administrativa (RECADM) - ISSN 1677-7387 \\ Faculdade Cenecista de Campo Largo - Coordenação do Curso de Administração v. 3, n. 2, nov./2004 - http://revistas.facecla.com.br/index.php/recadm/}

\section{5 - A universidade do século XXI rumo ao desenvolvimento sustentável}

O desafio do desenvolvimento sustentável procura, na universidade, um agente especialmente equipado para liderar o caminho, porque a sua missão é o ensino e a formação dos decisores do futuro ou dos cidadãos mais capacitados para a tomada de decisão, porque é rica e extensiva a sua experiência em investigação interdisciplinar e porque a sua natureza fundamental de motor do conhecimento lhe imprime um papel essencial num mundo cujas fronteiras se dissolvem a cada dia.

A Organização das Nações Unidas (ONU) deu os primeiros sinais às universidades quanto ao seu papel no caminho global para o desenvolvimento sustentável. Os documentos associados às Conferências em Desenvolvimento Humano em 1972 e em Ambiente e Desenvolvimento - UNCED em 1999 explicitam objetivos e medidas dirigidas às instituições de ensino superior (quadro 1).

\begin{tabular}{|c|c|c|}
\hline Documento & Objetivos & Medidas Recomendadas \\
\hline $\begin{array}{l}\text { UNCHD (1972) } \\
\text { Declaração de } \\
\text { Estocolmo } \\
\text { (Princípios } 9 \text { e 24) }\end{array}$ & $\begin{array}{l}\text { Prever e/ou minorar } \\
\text { aspectos contrários } \\
\text { ao desenvolvimento } \\
\text { sustentável. }\end{array}$ & $\begin{array}{l}\text { Formulação de acordos multi- ou bilaterais ou de } \\
\text { outras formas de cooperação (nomeadamente em } \\
\text { transferência tecnológica). }\end{array}$ \\
\hline $\begin{array}{l}\text { UNCED (1991) } \\
\text { Relatório do Comitê } \\
\text { Preparatório }\end{array}$ & $\begin{array}{l}\text { Envolver todos na } \\
\text { educação para o } \\
\text { desenvolvimento } \\
\text { sustentável. }\end{array}$ & $\begin{array}{l}\text { Envolvimento de decisores no governo, de } \\
\text { especialistas que os aconselhem nas universidades, } \\
\text { institutos de investigação, etc. }\end{array}$ \\
\hline $\begin{array}{l}\text { UNCED (1992) } \\
\text { Declaração do Rio } \\
\text { (Princípio 9) }\end{array}$ & $\begin{array}{l}\text { Fortalecer o } \\
\text { desenvolvimento de } \\
\text { capacidades para o } \\
\text { desenvolvimento } \\
\text { sustentável. }\end{array}$ & $\begin{array}{l}\text { Intercâmbio de conhecimento científico e tecnológico. } \\
\text { Desenvolvimento, adaptação, difusão e transferência } \\
\text { de tecnologias, incluindo as novas e inovativas. }\end{array}$ \\
\hline \multirow{3}{*}{$\begin{array}{l}\text { UNCED (1992) } \\
\text { Agenda } 21 \\
\text { (Capítulos 31, 34, } 35 \text { e } \\
\text { 36) }\end{array}$} & $\begin{array}{l}\text { Clarificar o papel da } \\
\text { ciência e tecnologia } \\
\text { no desenvolvimento } \\
\text { sustentável. }\end{array}$ & $\begin{array}{l}\text { (Re)desenho dos programas nacionais em Ciência e } \\
\text { Tecnologia por forma a clarificar contribuições do setor } \\
\text { para o desenvolvimento sustentável e identificar } \\
\text { funções/ responsabilidades do sector no } \\
\text { desenvolvimento humano. }\end{array}$ \\
\hline & $\begin{array}{l}\text { Gerar e disseminar } \\
\text { conhecimento e } \\
\text { informação em } \\
\text { desenvolvimento } \\
\text { sustentável. }\end{array}$ & $\begin{array}{l}\text { Produção de avaliações científicas de longo prazo } \\
\text { sobre depleção dos recursos, uso da energia, } \\
\text { impactos na saúde e tendências demográficas, e } \\
\text { tornar públicas em formas amplamente } \\
\text { compreendidas. }\end{array}$ \\
\hline & $\begin{array}{l}\text { Educar todos para o } \\
\text { desenvolvimento } \\
\text { sustentável. }\end{array}$ & $\begin{array}{l}\text { Desenvolvimento de programas de educação em } \\
\text { ambiente e desenvolvimento (acessível a pessoas de } \\
\text { todas as idades). Incentivos dos países às } \\
\text { universidades e a redes de trabalho neste âmbito. }\end{array}$ \\
\hline
\end{tabular}

Quadro I - A ONU e as universidades no âmbito do Desenvolvimento Sustentável (1972-1992)

Fonte:http:www.campus.unl.pt - Acesso em 26.09.2003

As universidades estão cada vez mais conscientes do papel que têm a desempenhar para preparar as novas gerações para um futuro viável. Nos anos 80, com a publicação do Relatório Brandtland e também da cúpula "Planeta Terra" do Rio, as universidades se esforçaram para definir e ao mesmo tempo assumir seu papel no que se refere ao ensino para um futuro viável. Com essa finalidade, 


\section{Revista Eletrônica de Ciência Administrativa (RECADM) - ISSN 1677-7387 Faculdade Cenecista de Campo Largo - Coordenação do Curso de Administração v. 3, n. 2, nov./2004 - http://revistas.facecla.com.br/index.php/recadm/}

em diferentes períodos e lugares, as universidades propuseram e adotaram declarações ambiciosas, onde apareciam os grandes princípios e objetivos do processo de reforma que estavam prontos a adotar. Neste sentido, pode-se citar os seguintes documentos como declarações para o desenvolvimento sustentável: a resposta das universidades:

5.1 - Declaração de Talloires - em outubro de 1990, vinte presidentes de universidades, os reitores e pró-reitores das universidades de todas as regiões do mundo mostraram seus interesses sobre a velocidade crescente da poluição e da degradação ambientais e a depleção de recursos naturais. Esta declaração foi assinada no Centro Europeu da Universidade de Tufts, Talloires, França.

Consta na declaração que as universidades têm um papel crucial na educação, investigação, formação de políticas e troca de informação necessárias à concretização destes objetivos e que os líderes universitários têm que garantir a liderança e apoio na mobilização dos recursos internos e externos, de forma a que as suas instituições respondam a este desafio urgente. Para isto tem as seguintes ações:

$\sqrt{ }$ aumentar a consciência para o desenvolvimento ambientalmente sustentável - usar todas as oportunidades para reforçar a consciência pública, governamental, industrial, institucional e universitária, defendendo publicamente a necessidade urgente de caminhar rumo a um futuro ambientalmente sustentável.

$\sqrt{ }$ criar uma cultura institucional da sustentabilidade - encorajar todas as universidades a envolver-se na educação, investigação, formação de políticas e troca de informação sobre a população, ambiente e desenvolvimento rumo a um futuro mais sustentável.

$\sqrt{ }$ educar para a cidadania ambientalmente responsável - estabelecer programas para produzir conhecimento em gestão ambiental, desenvolvimento econômico sustentável, população e domínios relacionados, de forma a assegurar que todos os graduados universitários sejam formados em ambiente e cidadãos responsáveis.

$\sqrt{ }$ incentivar a literatura ambiental - criar programas para desenvolver a capacidade do corpo docente de cada faculdade de ensinar matérias ambientais a todos os estudantes universitários.

$\sqrt{ }$ praticar a ecologia institucional - estimular os dirigentes universitários e os docentes e investigadores ambientais a desenvolver investigação, políticas, programas de intercâmbio de informação e curricular para um futuro ambientalmente sustentável.

$\sqrt{ }$ envolver todas as partes interessadas - encorajar governos, fundações e indústria a apoiar a investigação interdisciplinar, a educação, o desenvolvimento de políticas e o intercâmbio de informação em desenvolvimento ambientalmente sustentável. Expandir o trabalho com as comunidades locais e as organizações não governamentais para ajudar a encontrar soluções para os problemas ambientais. 


\section{Revista Eletrônica de Ciência Administrativa (RECADM) - ISSN 1677-7387 \\ Faculdade Cenecista de Campo Largo - Coordenação do Curso de Administração v. 3, n. 2, nov./2004 - http://revistas.facecla.com.br/index.php/recadm/}

$\sqrt{ }$ colaborar para abordagens interdisciplinares - reunir professores e gestores universitários com técnicos ambientais de forma a desenvolver abordagens interdisciplinares aos currículos e a iniciativas de investigação, operação e comunicação que suportem um futuro ambientalmente sustentável.

$\sqrt{ }$ aumentar a capacidade das escolas primárias e secundárias - estabelecer parcerias com as escolas primárias e secundárias para potenciar as capacidades dos seus professores em ensinar assuntos relacionados com a população, o ambiente e o desenvolvimento sustentável.

V. alargar o serviço e o alcance, nacional e internacionalmente - trabalhar com a Conferência da ONU em Ambiente e Desenvolvimento (UNCED), o Programa Ambiental da ONU (UNEP) e outras organizações internacionais e nacionais para promover um esforço universitário global rumo a um futuro sustentável

V. manter o movimento - estabelecer um comitê de acompanhamento e um secretariado para continuar este momentum, informar e apoiar mutuamente os esforços na efetivação desta declaração

Os signatários da Declaração de Talloires comprometem-se a criar uma cultura institucional da sustentabilidade, encorajando todas as universidades a envolverem-se na educação, investigação, formação de políticas e intercâmbio de informação em ambiente e desenvolvimento.

5.2 - Declaração de Halifax - um ano mais tarde, em dezembro de 1991, em Halifax - Canadá, os representantes sêniores da IAU - Associação Internacional das Universidades, da Universidade Unida das Nações e da Associação das Universidades e Faculdades do Canadá, juntaram-se com 20 presidentes das universidades das várias partes do mundo para discutir as seguintes ações a todas as universidades:

$\sqrt{ }$ utilizar os recursos intelectuais da universidade para incentivar uma compreensão melhor por parte da sociedade dos perigos físicos, biológicos e sociais relacionados que enfrentam o planeta Terra.

$\sqrt{ }$ enfatizar a obrigação ética da geração atual para superar aquelas mal práticas da utilização de recursos e daquelas circunstâncias difundidas do ser humano que se encontram na raiz da insustentabilidade ambiental.

$\sqrt{ }$ realçar a capacidade da universidade de ensinar e praticar princípios sustentáveis, para aumentar o interesse ambiental e para aumentar a compreensão da ética ambienta entre a faculdade, os estudantes e o público em geral.

$\sqrt{ }$ cooperar com todos os segmentos da sociedade e na perseguição de medidas práticas para conseguir a revisão e a reversão eficazes daquelas práticas da corrente que contribuem à degradação ambiental.

$\checkmark$ empregar todas as comunicações entre universidade, enfatizando estes empreendimentos à UNCED, aos governos e ao público em geral.

A Declaração de Halifax foi liberada na conclusão da conferência. 


\section{Revista Eletrônica de Ciência Administrativa (RECADM) - ISSN 1677-7387 Faculdade Cenecista de Campo Largo - Coordenação do Curso de Administração v. 3, n. 2, nov./2004 - http://revistas.facecla.com.br/index.php/recadm/}

5.3 - Declaração de Swansea - em agosto de 1993, na conclusão da conferência quinquenial das Universidades da Comunidade (ACU), os participantes expressaram a opinião de que as soluções aos problemas ambientais seriam eficazes se tivessem a participação de toda a sociedade na busca da sustentabilidade. Para isto desencadeou ações para:

$\sqrt{ }$ incitar as universidade da ACU a procurar estabelecer e disseminar uma compreensão mais desobstruída do desenvolvimento sustentável - desenvolvimento que se encontra com as necessidades do presente sem comprometer as necessidades das gerações futuras e incentivar os princípios e as práticas sustentáveis mais apropriadas do desenvolvimento nos níveis locais, nacionais e globais, nas maneiras consistentes com suas missões.

$\sqrt{ }$ utilizar recursos da universidade incentivando à melhor compreensão por parte dos governos e do público, sobre grandes perigos físicos, biológicos e sociais relacionados que enfrentam a Terra e para reconhecer a interdependência significativa e as dimensões internacionais do desenvolvimento sustentável.

$\sqrt{ }$ enfatizar a obrigação ética da geração atual para superar aquelas práticas da utilização do recurso e aquelas circunstâncias difundidas.

$\sqrt{ }$ realçar a capacidade da universidade de ensinar e praticar princípios sustentáveis, para aumentar o interesse ambiental e para aumentar a compreensão da ética ambiental entre a faculdade, os estudantes e o público em geral.

$\sqrt{ }$ cooperação com todos os segmentos da sociedade e perseguição de medidas práticas para conseguir a revisão e a reversão eficazes daquelas práticas da corrente que contribuem à degradação ambiental.

$\sqrt{ }$ incentivar universidades a rever suas próprias operações para refletir as melhores práticas sustentáveis

$\sqrt{ }$ pedir urgente ao conselho da ACU para considerar e executar as maneiras e os meios, dar vida a esta declaração na missão de cada um de seus membros e com a empresa comum da ACU.

Esta declaração foi feita na Universidade do Wales, Swansea, no dia 20 de agosto de 1993, e já foi liberada na conclusão da Associação da Conferência das Universidades.

5.4 - Acordos da Conferência da Terra - Até a Conferência do Rio (UNCED), as universidades praticamente estiveram fora do palco da discussão sobre o desenvolvimento sustentável. A experiência trouxe uma lição clara: as universidades não se devem esquivar ao desafio, pois de acordo com Associação Internacional das Universidades - IAU, 1993, se não nos envolvermos, se não usarmos as nossas forças combinadas para ajudar a resolver os problemas emergentes da nossa sociedade global, então seremos ignorados no despertar de um outro motor de mudança, uma outra agência ou estrutura 


\section{Revista Eletrônica de Ciência Administrativa (RECADM) - ISSN 1677-7387 Faculdade Cenecista de Campo Largo - Coordenação do Curso de Administração v. 3, n. 2, nov./2004 - http://revistas.facecla.com.br/index.php/recadm/}

que será convidada a promover a liderança. Agenda 21 local - capítulo 36 - promover a educação, a consciência pública e a formação. Área programática - reorientar a educação para o desenvolvimento sustentável - ONU, 1992. Bases para a ação:

$\sqrt{ }$ a educação, incluindo a educação formal, a consciência pública e a formação devem ser reconhecidas como um processo através do qual os seres humanos e as sociedades podem alcançar o seu completo potencial.

$\sqrt{ }$ a educação é vital à promoção do desenvolvimento sustentável e à melhoria das capacidades humanas em lidar com as questões do ambiente e do desenvolvimento.

$\sqrt{ }$ enquanto a educação básica fornece as bases para qualquer educação em ambiente e desenvolvimento, as posteriores necessitam ser incorporadas como uma parte essencial da aprendizagem.

$\sqrt{ }$ a educação formal e a educação não-formal são ambas indispensáveis na mudança de atitudes que capacitará as pessoas a avaliar e resolver as suas preocupações de desenvolvimento sustentável.

$\sqrt{ }$ a educação é também vital ao alcance de uma ética e consciência ambiental, de valores e atitudes, habilidades e comportamentos consistentes com o desenvolvimento sustentável e para uma efetiva participação pública nos processos decisórios.

$\sqrt{ }$ para ser efetiva, a educação ambiental e de desenvolvimento deve lidar com as dinâmicas biofísicas e socioeconômicas do ambiente e de desenvolvimento (que pode também ser espiritual) humano, deve ser integrada em todas as disciplinas e deve empregar métodos formais e não-formais e meios efetivos de comunicação.

5.5 - Declaração de Kyoto - promovida pela Associação Internacional das Universidades (IAU), sublinha a dimensão ética da educação para o desenvolvimento sustentável que, além de ensinar princípios, deve promover práticas igualmente sustentáveis. Na 9a Mesa Redonda da IAU, que ocorreu em Kyoto (Japão) a 19 de novembro de 1993, cerca de 90 líderes universitários reuniram-se para discutir e adotar uma declaração de princípios, baseada nas declarações emanadas das conferências de Talloires (1990), Halifax (1991) e Swansea (1993). As ações foram as seguintes:

$\sqrt{ }$ pressionar as universidades em todo o mundo a procurar estabelecer e disseminar uma compreensão mais clara do conceito de «desenvolvimento sustentável» - «o desenvolvimento que satisfaz as necessidades do presente sem comprometer as necessidades das gerações futuras» - e encorajar princípios e práticas de desenvolvimento sustentável mais apropriados ao nível local, nacional e global, de formas mais concentâneas com as suas missões.

$\sqrt{ }$ utilizar os recursos das universidades para encorajar uma melhor compreensão, por parte dos governos e do público em geral, dos perigos inter-relacionados físicos, biológicos e sociais que ameaçam 


\section{Revista Eletrônica de Ciência Administrativa (RECADM) - ISSN 1677-7387 Faculdade Cenecista de Campo Largo - Coordenação do Curso de Administração v. 3, n. 2, nov./2004 - http://revistas.facecla.com.br/index.php/recadm/}

o planeta Terra e para reconhecer a interdependência significativa e as dimensões internacionais do desenvolvimento sustentável.

$\sqrt{ }$ sublinhar a obrigação ética da geração presente em ultrapassar as práticas de utilização dos recursos e as disparidades globalmente disseminadas que estão na base da insustentabilidade ambiental.

$\sqrt{ }$ potenciar a capacidade da universidade de ensinar, investigar e agir no seio da sociedade, de acordo com os princípios de desenvolvimento sustentável; aumentar a literatura ambiental e melhorar a compreensão da ética ambiental no meio acadêmico e entre o público em geral.

$\sqrt{ }$ cooperar entre si e com todos os segmentos da sociedade na procura de medidas práticas e de política que alcancem o desenvolvimento sustentável e assim assegurem os interesses das gerações futuras.

$\sqrt{ }$ encorajar as universidades a rever as suas próprias operações de forma a refletir as melhores práticas de desenvolvimento sustentável.

$\sqrt{ }$ solicitar ao conselho administrativo da IAU que considere e implemente as formas e meios adequados à vitalização da presente Declaração, refletida na missão de cada um dos seus membros e na política conjunta da IAU.

5.6 - Carta Copernicus - A Carta Copernicus, chamada de Carta Patente da Universidade para o Desenvolvimento Sustentável, define os princípios de ação a serem adotados pelas universidades rumo ao desenvolvimento sustentável. O Programa Copernicus (Cooperation Program for Environmental Research in Nature and Industry through Coordinated University Studies) é um programa de cooperação européia para a pesquisa sobre a natureza e a indústria com os estudos coordenados da universidade e foi lançado pela Conferência dos Reitores da Europa (CRE) em 1988.

Este programa é o principal agente regional em diálogo nesta matéria a nível internacional e trabalha em parceria com a Associação das Universidades Européias (EUA), o Instituto de Investigação para a Europa Sustentável (SERI), a Associação Ambiental das Universidades e Faculdades do Reino Unido (EAUC) e algumas universidades singularmente proativas em desenvolvimento sustentável no espaço europeu.

Tendo como visão tornar a sustentabilidade uma marca registrada tanto do espaço europeu da investigação como do espaço europeu da educação, o programa Copernicus desenvolve a sua própria estratégia de ação consubstanciada nos princípios de sua carta, conforme quadro 2.

\begin{tabular}{|l|l|l|l|}
\hline Objetivos gerais & Prioridades & Áreas-chave & Ações Copernicus \\
\hline
\end{tabular}


Revista Eletrônica de Ciência Administrativa (RECADM) - ISSN 1677-7387

Faculdade Cenecista de Campo Largo - Coordenação do Curso de Administração

v. 3, n. 2, nov./2004 - http://revistas.facecla.com.br/index.php/recadm/

\begin{tabular}{|c|c|c|c|}
\hline \multirow{3}{*}{$\begin{array}{lr}\text { Identificar formas de } \\
\text { as universidades } \\
\text { ajudarem } \\
\text { sociedade } & \text { a } \\
\text { responder ao desafio } \\
\text { do desenvolvimento } \\
\text { sustentável }\end{array}$} & $\begin{array}{l}\text { Gerar } \\
\text { conhecimento } \\
\text { em } \\
\text { desenvolvimento } \\
\text { sustentável }\end{array}$ & $\begin{array}{l}\text { Investigação multidisciplinar } \\
\text { Redes de peritos }\end{array}$ & $\begin{array}{lr}\text { Seminário virtual } & \text { em } \\
\text { expansão } & \mathrm{e} \\
\text { desenvolvimento } \\
\text { sustentável }\end{array}$ \\
\hline & $\begin{array}{l}\text { Disseminar } \\
\text { conhecimento } \\
\text { em } \\
\text { desenvolvimento } \\
\text { sustentável aos } \\
\text { alunos } \\
\end{array}$ & $\begin{array}{l}\text { Formação de professores } \\
\text { Currículos universitários em } \\
\text { desenvolvimento sustentável }\end{array}$ & \\
\hline & $\begin{array}{l}\text { Disseminar } \\
\text { conhecimento } \\
\text { em } \\
\text { desenvolvimento } \\
\text { sustentável à } \\
\text { sociedade }\end{array}$ & $\begin{array}{l}\text { Parcerias e redes de trabalho a } \\
\text { nível local } \\
\text { Serviço à sociedade em: } \\
\text {-ciência e investigação; } \\
\text {-definição de políticas; } \\
\text { desenvolvimento de capacidades; } \\
\text {-transferência tecnológica }\end{array}$ & $\begin{array}{l}\text { Conferências anuais, } \\
\text { desde 1998: } \\
\text { Sustainable Universities: } \\
\text { inter-, multi-and trans- } \\
\text { disciplinary issues and } \\
\text { options, (Barcelona, } \\
\text { 1999) }\end{array}$ \\
\hline $\begin{array}{lr}\text { Alcançar } & \text { a } \\
\text { sustentabilidade } & \text { nas } \\
\text { universidades } & \end{array}$ & $\begin{array}{l}\text { Implementar } \\
\text { práticas } \\
\text { ambientalmente } \\
\text { responsáveis } \\
\text { pelas e nas } \\
\text { universidades }\end{array}$ & $\begin{array}{l}\text { Promover a gestão ambiental das } \\
\text { universidades } \\
\text { Promover padrões sustentáveis de } \\
\text { produção e consumo nas } \\
\text { universidades }\end{array}$ & $\begin{array}{l}\text { Projetos: } \\
\text {-Universidade de baixa } \\
\text { energia; } \\
\text {-Campus-solar europeu } \\
\text {-Química sustentável }\end{array}$ \\
\hline
\end{tabular}

Fonte: http://www.copernicus-campus.org Acesso em 27.09.2003.

Quadro 2 - Estratégia do Programa Copernicus para o Desenvolvimento Sustentável

A carta patente foi introduzida e apresentada à Conferência Bianual de CRE em Barcelona em outubro de 1993 e assinada em Genebra em abril de 1994 por um conjunto de 196 universidades européias.

5.6.1 - Preâmbulo - A exploração da biosfera pelo homem ameaça hoje a sua própria existência. Ao longo das últimas décadas, as pressões sobre o ambiente global tornaram-se auto-evidentes, fazendo erguer uma voz comum pelo desenvolvimento sustentável. Nas palavras do Relatório Bruntland, nós temos que aprender a cuidar das necessidades presentes sem comprometer a capacidade das gerações futuras de em qualquer parte satisfazerem as suas próprias necessidades.

A consciência está aí. O que falta é uma estratégia compreensível para construir um futuro sustentável eqüitativo para todos os seres humanos, como foi sublinhado pela Conferência do Rio (UNCED) e pela Conferência das Nações Unidas sobre o Desenvolvimento Ambiental, em 1992. Essa estratégia requer um novo enquadramento mental e novo conjunto de valores.

A educação é essencial à promoção de tais valores e para aumentar as capacidades das pessoas de enfrentar as questões ambientais e de desenvolvimento. A educação em todos os níveis, especialmente a educação universitária para a formação de decisores e professores, deve ser orientada para o desenvolvimento sustentável e para forjar atitudes, padrões de capacidade e comportamentos 


\section{Revista Eletrônica de Ciência Administrativa (RECADM) - ISSN 1677-7387 Faculdade Cenecista de Campo Largo - Coordenação do Curso de Administração v. 3, n. 2, nov./2004 - http://revistas.facecla.com.br/index.php/recadm/}

ambientalmente conscientes, tal como um sentido de responsabilidade ética. A educação tem que se tornar educação ambiental no sentido mais lato do termo.

5.6.2 - O papel das universidades - As universidades e equivalentes instituições de ensino superior formam as futuras gerações de cidadãos e possuem conhecimentos de especialidade em todos os campos da investigação, tanto em tecnologia como nas ciências naturais, humanas e sociais.

É conseqüentemente seu dever propagar a literatura ambiental e promover a prática de uma ética ambiental na sociedade, em concordância com os princípios definidos na Magna Carta das Universidades Européias e subseqüentes declarações universitárias e com as recomendações da UNCED para o ambiente e o desenvolvimento.

$\mathrm{Na}$ verdade, as universidades são cada vez mais chamadas a desempenhar um papel preponderante no desenvolvimento de uma forma de educação multidisciplinar e eticamente orientada, de forma a encontrar soluções para os problemas ligados ao desenvolvimento sustentável. Elas devem, portanto, assumir um compromisso para com um processo contínuo de informação, educação e mobilização de todas as partes relevantes da sociedade com relação às conseqüências da degradação ecológica, incluindo o seu impacto sobre o ambiente global e as condições que garantem um mundo sustentável e justo.

Para alcançar estes objetivos e cumprir a sua missão básica, as universidades são pressionadas a desencadear todos os esforços para subscrever e implementar os dez princípios de ação abaixo definidos.

$\sqrt{ }$ compromisso institucional - as universidades devem demonstrar um compromisso real para com a teoria e a prática da proteção ambiental e do desenvolvimento sustentável no seio da comunidade acadêmica.

$\sqrt{ }$ ética ambiental - as universidades devem promover, entre os seus docentes, alunos e o público em geral, padrões de consumo sustentáveis e um estilo de vida ecológico, estimulando paralelamente programas que desenvolvam as capacidades do corpo docente para ensinar literatura ambiental.

$\sqrt{ }$ educação dos funcionários universitários - as universidades deverão proporcionar educação, formação e encorajamento aos seus funcionários em matérias ambientais, para que eles possam prosseguir o seu trabalho de uma forma ambientalmente responsável.

$\sqrt{ }$ programas de educação ambiental - as universidades deverão incorporar uma perspectiva ambiental em todo o seu trabalho e estabelecer programas de educação ambiental envolvendo docentes, investigadores e estudantes, expondo-os a todos os desafios globais do ambiente e desenvolvimento, seja qual for o seu campo de trabalho ou estudo.

$\sqrt{ }$ interdisciplinaridade - as universidades devem encorajar a educação interdisciplinar e colaborativa e programas de investigação relativos ao desenvolvimento sustentável enquanto parte da missão central 


\section{Revista Eletrônica de Ciência Administrativa (RECADM) - ISSN 1677-7387 Faculdade Cenecista de Campo Largo - Coordenação do Curso de Administração v. 3, n. 2, nov./2004 - http://revistas.facecla.com.br/index.php/recadm/}

da instituição. Devem também procurar ultrapassar os instintos competitivos entre disciplinas e departamentos.

$\sqrt{ }$ disseminação do conhecimento - as universidades devem apoiar esforços para suprir as falhas na atual literatura disponível aos estudantes, profissionais, decisores e público em geral, preparando material didático informativo, organizando leituras públicas e estabelecendo programas de formação. Elas devem também estar preparadas para participar em auditorias ambientais.

$\sqrt{ }$ redes de trabalho - as universidades devem promover redes interdisciplinares de peritos ambientais ao nível local, nacional, regional e internacional, com o objetivo de colaborar em projetos ambientais comuns de ensino e investigação. Para isto, a mobilidade de estudantes deve ser encorajada.

$\sqrt{ }$ parcerias - as universidades deverão tomar a iniciativa de forjar parcerias com outros setores preocupados da sociedade, de modo a desenhar e implementar abordagens, estratégias e planos de ação coordenados.

$\sqrt{ }$ programas de educação contínua - as universidades deverão inventar programas de educação ambiental sobre estes assuntos e para diferentes grupos-alvo, por exemplo: empresas, agências governamentais, organizações não-governamentais, meios de comunicação social.

$\sqrt{ }$ transferência tecnológica - as universidades devem contribuir para programas educacionais concebidos para a transferência de tecnologias de educação e inovação e métodos de gestão avançados.

5.7 - Declaração dos estudantes para um futuro sustentável - organizado pelo CEED - Comunidade Ambiental de Desenvolvimento Educacional, esta Declaração ganhou respaldo no Reino Unido, na Universidade de Sunderland, com 80 pessoas de 34 universidades e faculdades britânicas nos dias 2 a 5 de julho de 1995. Foi discutida a responsabilidade ambiental dos estudantes na tentativa particular de moldar uma declaração abrangendo ações mais adicionais. Nessa época, os participantes da conferência desenvolveram guias para a ação, tendo como o começo de um acoplamento entre estudantes e as agendas ambientais institucionais e internacionais.

5.8 - Parceria Global do Ensino Superior para o Desenvolvimento Sustentável - GHESP - esta parceria foi formada em 2000 pela ULSE - University Leaders for a Sustainable Future - Universidade Líder para um Futuro Sustentável, Copernicus-campus, IAU - Associação Internacional das Universidades e UNESCO - Organização das Nações Unidas para a Educação, a Ciência e a Cultura, em resultado do programa de trabalho da Comissão para o Desenvolvimento Sustentável das Nações Unidas (CSD-UM) e antecipando a Conferência Mundial sobre Desenvolvimento Sustentável (WSSD). Essa parceria teve como primeiro produto a Declaração de Luneburg em 10 de outubro de 2001. Esta Declaração é a instrução mais elevada para o desenvolvimento sustentável. 


\section{Revista Eletrônica de Ciência Administrativa (RECADM) - ISSN 1677-7387 Faculdade Cenecista de Campo Largo - Coordenação do Curso de Administração v. 3, n. 2, nov./2004 - http://revistas.facecla.com.br/index.php/recadm/}

5.9 - Declaração de Luneburg - esta declaração, emanada da Conferência sobre o Ensino Superior para o Desenvolvimento Sustentável, relembra os compromissos assumidos e, num esforço de efetivar o seu cumprimento, define metas concretas a atingir pela GHESP, em representação de mais de 1.000 universidades a nível mundial, até 2006. Dentre estas metas, salientam-se:

$\checkmark$ criar um ambiente de aprendizagem global para o ensino superior para o desenvolvimento sustentável; $\checkmark$ produzir um pacote de ferramentas orientadas para a ação universitária, incluindo estratégias de implementação à medida, estratégias para a reforma em áreas específicas da atividade universitária, um inventário dos recursos disponíveis e outro de melhores práticas e casos de estudo.

A criação da GHESP e o seu trabalho comprovam que, antes de educar cidadãos para enfrentar o desafio do desenvolvimento sustentável, importa educar as universidades para assumirem a sua missão nesse desafio.

5.10 - Declaração de UBUNTU - dirige um apelo à ONU em 2002, no sentido de esta designar os educadores como o décimo grupo de intervenientes-chave no processo da Conferência Mundial sobre o Desenvolvimento Sustentável de Joanesburgo - WSSD. E reforça o compromisso das universidades na criação de um espaço de aprendizagem global em educação e sustentabilidade, a se desenvolver com base em redes internacionais e mediante a criação de centros de excelência regionais que congreguem todas as instituições formais de ensino, do fundamental ao superior.

5.11 - Conferências Internacionais sobre Gestão Ambiental para as Universidades Sustentáveis EMSU - conferência-franja da Conferência WSSD, em 2002 na África do Sul, reuniu 150 delegados em torno da pergunta: qual o papel do ensino superior no desenvolvimento sustentável? Uma resposta particular mereceu especial atenção e foi apresentada pela Universidade Politécnica da Catalunha, sob a seguinte forma, conforme mostra a figura 2 . 


\section{Revista Eletrônica de Ciência Administrativa (RECADM) - ISSN 1677-7387}

Faculdade Cenecista de Campo Largo - Coordenação do Curso de Administração v. 3, n. 2, nov./2004 - http://revistas.facecla.com.br/index.php/recadm/

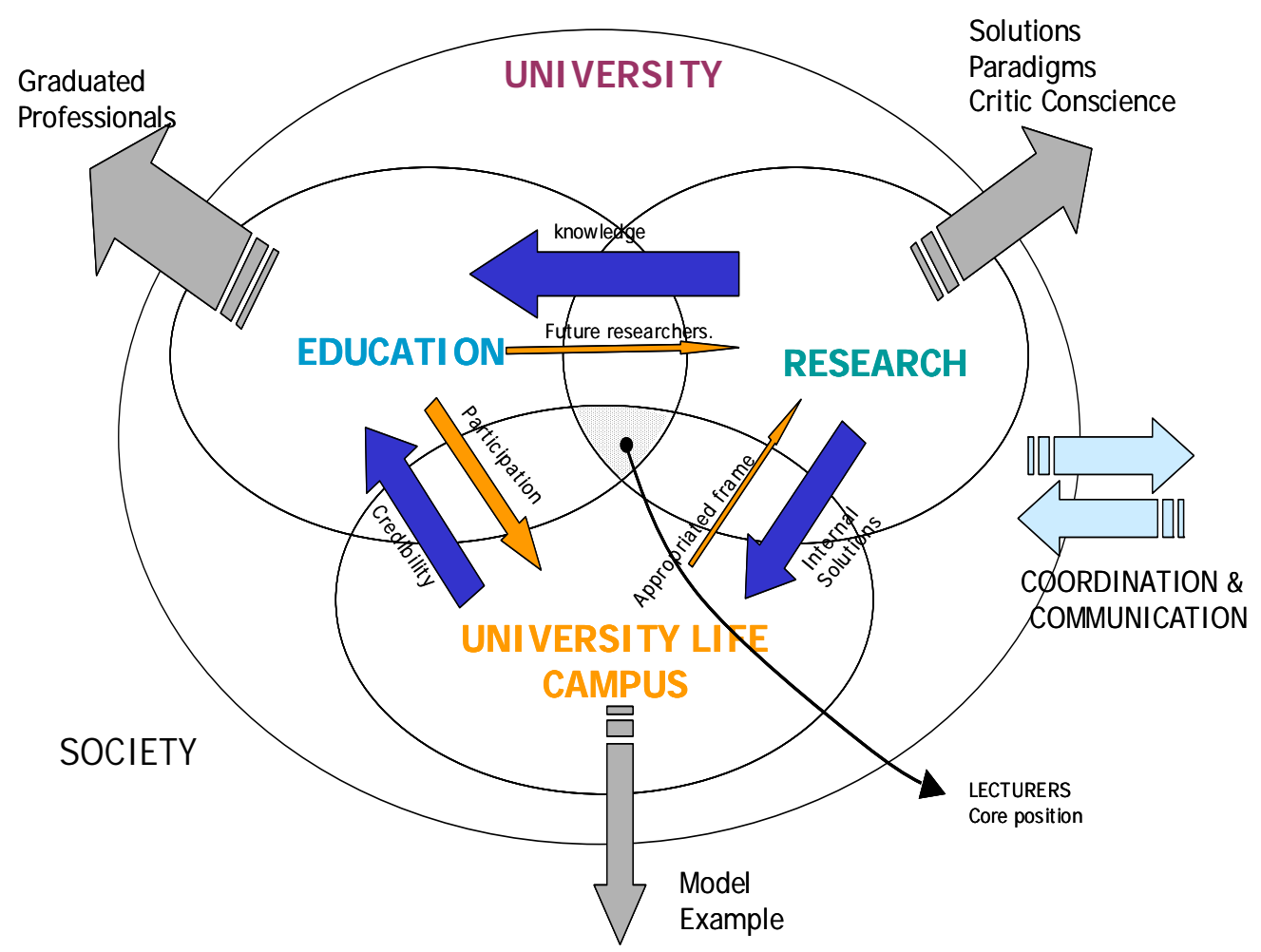

Fonte: http://www.campus.unl.pt. Acesso em 26.09.2003

Figura 2 - O papel da universidade na sociedade, relativamente ao desenvolvimento sustentável

Neste modelo, surgem distintos quatro níveis de intervenção para as universidades:

1 - educação dos decisores para um futuro sustentável;

2 - investigação de soluções, paradigmas e valores que sirvam uma sociedade sustentável;

3 - operação dos campus universitários como modelos e exemplos práticos de sustentabilidade à escala local;

4 - coordenação e comunicação entre os níveis anteriores e entre estes e a sociedade.

Neste sentido, as universidades são diariamente chamadas a exercer um papel de liderança na proposição de uma forma de educação inter(trans) disciplinar que comporte uma dimensão ética e que tenha por objetivo conceber soluções para os problemas ligados ao desenvolvimento sustentável.

\section{6 - Conclusão}

Ao longo das últimas décadas, as pressões sobre o ambiente global tornaram-se autoevidentes, fazendo erguer uma voz comum pelo desenvolvimento sustentável. Essa estratégia requer um novo enquadramento mental e novo conjuntos de valores. 


\section{Revista Eletrônica de Ciência Administrativa (RECADM) - ISSN 1677-7387 Faculdade Cenecista de Campo Largo - Coordenação do Curso de Administração v. 3, n. 2, nov./2004 - http://revistas.facecla.com.br/index.php/recadm/}

A educação é essencial à promoção de tais valores e para aumentar as capacidades das pessoas de enfrentar as questões ambientais e de desenvolvimento. A educação em todos os níveis, especialmente a educação universitária para a formação de gestores e professores, deve ser orientada para o desenvolvimento sustentável e para forjar atitudes, padrões de capacidade e comportamentos ambientalmente conscientes, tal como um sentido de responsabilidade ética.

Todos os estabelecimentos de ensino superior estão bastante conscientes do papel que devem cumprir na preparação das novas gerações para um futuro sustentável. As universidades envolvidas partilham a convicção de que o progresso econômico e a proteção ambiental estão indissoluvelmente ligados.

Neste sentido, as universidades são diariamente chamadas a exercer um papel de liderança na proposição de uma forma de educação inter(trans)disciplinar que comporte uma dimensão ética e que tenha por objetivo conceber soluções para os problemas ligados ao desenvolvimento sustentável.

A universidade é, dentre as várias instituições de ensino formal, aquela à qual compete ministrar o mais elevado grau de ensino, o superior, ou seja, o da educação para máxima capacitação e qualificação dos seus cidadãos na resolução e antecipação dos problemas que mais a afetam. E para cumprir esta missão, a universidade busca incessantemente as raízes e soluções desses problemas, por meio da investigação e do desenvolvimento de metodologias e ferramentas novas e inovativas.

Fouto (2003) diz que o ensino é o cerne da atividade da universidade e a educação a sua missão primeira. Face aos objetivos de desenvolvimento sustentável, a educação para o desenvolvimento sustentável será, portanto, o principal papel da universidade no século XXI.

\section{Referências}

BATESON, G. Natureza e espírito. Lisboa: Dom Quixote, 1987.

BERTALANFFY, L. V. Teoria Geral dos Sistemas. São Paulo: Vozes, Petrópoles, 1977

DIAS, Genebaldo F. Educação ambiental: princípios e práticas: São Paulo: Gaia, 1993.

FOUTO, A. R. F. O papel das univesidades . http://www.campusverde/pt - acesso em 26.09.2003.

GONZÁLEZ, C. L. ABADÍA, J. M. M. Global Reporting Iniciative: Contabilidad y Sostenibilidad. Revista Partida Doble. n. 135, p. 80-87, jul/ago. 2002. www.partidadoble.es. Acesso em 15.06.2003.

KORNHAUSER, A. Criar oportunidades. Educação um tesouro a descobrir. 6. ed. São Paulo: Cortez; Brasília, DF: MEC: UNESCO, 2001.

MATURANA, H. Emoções e linguagem na educação e na política. Tradução de Fernando Campos Fortes. Belo Horizonte: Ed. UFMG, 1998.

MAYOR, F. Preparar um futuro viável: ensino superior e desenvolvimento sustentável. In: Conferência mundial sobre o ensino superior. Tendências de educação superior para o século XXI. Anais da Conferência Mundial do Ensino Superior. Paris: 1998. 
Revista Eletrônica de Ciência Administrativa (RECADM) - ISSN 1677-7387

Faculdade Cenecista de Campo Largo - Coordenação do Curso de Administração v. 3, n. 2, nov./2004 - http://revistas.facecla.com.br/index.php/recadm/

MORIN, E. Os sete saberes necessários à educação do futuro. www.centrorefeducacional,pro.br. Acesso em 25.08.2003.

http://www.copernicus-campus.org. - acesso em 27.09.2003

http://www.campus.unl.pt - acesso em 26.09.2003 